\title{
Pain, disease severity and associations with individual quality of life in patients with motor neuron diseases
}

\author{
Ylva Åkerblom ${ }^{1}$, Lena Zetterberg ${ }^{1}$, Birgitta Jakobsson Larsson², Dag Nyholm³ ${ }^{3}$ Ingela Nygren ${ }^{3}$ and
} Pernilla Åsenlöf ${ }^{*}$

\begin{abstract}
Background: Up to 85\% of people with motor neuron disease (MND) report pain, but whether pain has negative impact on quality of life is unclear. The aim was to study associations between pain, disease severity and individual quality of life (IQOL) in patients with MND.

Methods: In this cross sectional study, 61 patients were recruited from four multidisciplinary teams in Sweden, whereof 55 responded to the pain measure (The Brief Pain Inventory - Short form) and were included in the main analyses. Disease severity was measured with the Amyotrophic Lateral Sclerosis Functional Rating Scale - Revised Version, and individual quality of life was measured with a study-specific version of the Schedule for the Evaluation of Individual Quality of Life - Direct Weighting.

Results: Forty-one (74\%) of the participants who answered BPI-SF ( $n=55)$ reported pain. Thirty-nine (71\%) of those reported pain during the past $24 \mathrm{~h}$. The severity of pain was on average moderate, with eight participants (14\%) reporting severe pain $(\mathrm{PSI} \geq 7$ ).

Satisfaction with IQOL for the entire sample was good (scale 1-7, where 1 equals poor quality of life): median 5, interquartile range (IQR) 2.75 and there was no difference in satisfaction with $\mathrm{QQOL}$ between those reporting pain/not reporting pain (median 5, IQR 2/median 5, IQR 3.5, Mann-Whitney $U=249, p=0.452$ ). There was neither any correlation between pain severity and satisfaction with IQOL, nor between disease severity and satisfaction with IQOL.
\end{abstract}

Conclusions: The results add to the hypothesis that associations between non-motor symptoms such as pain prevalence and pain severity and IQOL in MND are weak. Pain prevalence was high and the results pointed to that some participants experienced high pain severity, which indicate that pain assessments and pain treatments tailored to the specific needs of the MND population should be developed and scientifically evaluated.

Keywords: Amyotrophic lateral sclerosis (ALS), Palliative diseases, Individual quality of life, Pain, Disease severity

*Correspondence: pernilla.asenlof@neuro.uu.se

'Department of Neuroscience, Physiotherapy, Uppsala University, Box 593 BMC, 75124 Uppsala, Sweden

Full list of author information is available at the end of the article

\section{Background}

Motor neuron disease (MND) is due to degeneration of motor neurons in the spinal cord, brainstem and motor cortex. Symptom representation varies but commonly includes muscle wasting, weakness, spasticity, cramps, dyspnea, dysarthria, and dysphagia [1]. Besides motor symptoms, anxiety, depression, limited cognitive function, and sensory disturbances e.g. pain, may also be

(c) The Author(s) 2021. Open Access This article is licensed under a Creative Commons Attribution 4.0 International License, which permits use, sharing, adaptation, distribution and reproduction in any medium or format, as long as you give appropriate credit to the original author(s) and the source, provide a link to the Creative Commons licence, and indicate if changes were made. The images or other third party material in this article are included in the article's Creative Commons licence, unless indicated otherwise in a credit line to the material. If material is not included in the article's Creative Commons licence and your intended use is not permitted by statutory regulation or exceeds the permitted use, you will need to obtain permission directly from the copyright holder. To view a copy of this licence, visit http://creativecommons.org/licenses/by/4.0/ The Creative Commons Public Domain Dedication waiver (http://creativeco mmons.org/publicdomain/zero/1.0/) applies to the data made available in this article, unless otherwise stated in a credit line to the data. 
present [1, 2]. Amyotrophic lateral sclerosis (ALS) is the most common MND diagnosis with a survival from symptom onset to usually 3-5years [1]. The incidence for ALS in Europe is estimated to $2.2 / 100000$ persons a year [3] and the prevalence is around 6/100000 [4]. Primary Lateral Sclerosis (PLS) is another MND which affects the upper motor neurons with spasticity of the limbs as primary symptom. Persons with PLS have more benign prognosis than those with ALS [5]. There are also other rare subtypes of MND, only affecting lower motor neurons, for instance progressive spinal muscular atrophy (PSMA). Motor neuron disease is incurable, which means that palliative care often starts when the patient has received the diagnosis [6].

Pain is common in MND and affects up to $85 \%$ of the MND population [7-11]. Pain seems to be present in all stages of the disease [12,13]. The severity of pain is reported mild to moderate $[2,7-10]$ and appears to affect personal daily functioning $[7,8,10]$. Even though the World Health Organization's (WHO) definition of palliative care underlines the importance of measures for pain relief [14], there is no evidence based pharmacological treatment for pain in ALS [15]. Nonpharmacological intervention studies are few and do not support one treatment over the other [16-18], and treatment recommendations are based on guidelines for non-cancer chronic pain combined with clinical experience of treating patients with ALS and pain [19].

Health related quality of life (HRQOL) concerns aspects of physical, mental and social functioning on health [20] and thereby includes how disease affects disability and every day function [21, 22]. Health related quality of life in people with MND worsen during disease progression [23, 24]. In degenerative neuromuscular diseases, an awareness regarding the potential inappropriateness of asking people about their HRQOL has emerged. Instead, individual quality of life (IQOL) is emphasized as more relevant, since it encompasses the personal and unique meaning of what constitutes QOL [25]. More precisely, IQOL focuses on a person's own perspectives of QOL, based on areas in life considered to be important at the present time [26]. Important areas of IQOL in people with MND are family, social activities and psychosocial functioning [27-31]. Despite the severe and fatal prognosis, people with MND consistently rate their IQOL as high during the course of the disease [30-32]. Hence, the physical deterioration due to disease progression does not seem to affect IQOL in people with MND [29, 30, 32, 33]. A shift in values regarding what is important in life when suffering from an incurable disease, might be the explanation to a maintained high IQOL throughout disease progression [25].
Research on associations between pain and QOL in people with MND show ambiguous results. Ganzini et al. reported that pain correlated to suffering, but not to QOL [34]. Another study showed that pain did not correlate to QOL [2], while a third study found that higher pain intensity predicted worse QOL until controlling for depression [11]. To our knowledge there are no studies on associations between pain and IQOL in people with MND. Such knowledge is regarded as key in palliative care for people with MND, which motivated the present study.

\section{Methods}

The aim was to study associations between pain prevalence, pain severity, disease severity and IQOL in patients with MND.

\section{Design}

The design was correlational using interview and survey data from the first point of measurement in a prospective study with all in all five measurement occasions. Nonparametrical statistical analyses were used for the main analyses, whereas data on what constitute IQOL were analyzed qualitatively.

\section{Settings and participants}

Patients were recruited from four multidisciplinary MND teams in Sweden from September 2015 to September 2016 . The sample size was determined by number of eligible participants enrolled in the four teams during this time period. In accordance with ordinary routines, the patients were scheduled for meetings with either the whole or a part of the team about every 10 weeks. The teams were multidisciplinary including a neurologist, a nurse, a physiotherapist, an occupational therapist, a social worker, a speech therapist and a dietician.

Patients, who had a scheduled visit to any of the MND teams during the recruitment period, had an MND diagnosis [4] and were over 18 years old were asked to participate in the study. The patients could be in different stages of the disease. Patients with Kennedy's disease were excluded mainly due to the sensory impact of the disease that might affect their perception of pain in a different way compared to the other motor neuron diseases included [35]. Patients with impact on cognitive function, i.e. difficulties in understanding the instructions for the study; patients with difficulties in understanding or expressing themselves in Swedish and patients with another neurological disease affecting the symptoms of the MND, were also excluded. 


\section{Measures}

Individual quality of life was assessed with a study-specific version of the Schedule for the Evaluation of Individual Quality of Life Direct Weighting (study-specific SEIQoL-DW) [26, 36]. The instrument is based on a semi-structured interview and started with an open question; "If you think about your whole life situation as it is right now, what are the most important areas, both good and bad, that are vital for your quality of life?" [26]. Thereafter, participants were asked to: 1 . identify the most important areas of quality of life, and describe the meaning of each area, 2. select five of the areas, which currently are the most important, 3. rate how satisfied you are with respect to each of the five areas [26]. The original version includes a weighting procedure that was omitted in this study-specific version, since it does not seem to impact the total index of IQOL [37]. Level of satisfaction was rated on seven-point categorical scales, with the following response format: $1=$ "as bad as could possibly be", 2 = "very bad", 3= "bad", 4= "fairly good", $5=$ "good", $6=$ "very good" and $7=$ "as good as could possibly be" [36]. The study-specific version used categorical scales instead of the original visual analogue scales to decrease efforts and motor skills required from the respondent. The latter require that a line is drawn corresponding to level of satisfaction for each scale, which can be demanding for participants with decreased motor function.

An IQOL score was calculated for each participant using the median of the ratings for the five areas. The IQOL index score for the total sample was then calculated using the median of the IQOL scores [37]. The SEIQoL-DW has been presented as a valid measure for measuring IQOL in different diagnoses including ALS $[38,39]$.

Pain was measured with the Short Form of Brief Pain Inventory (BPI-SF) [40]. The BPI-SF measures the presence of pain, pain severity, body regions affected, treatments for pain and pain interference in different activities [40]. In the present study, three subscales were used; presence of pain during the past $24 \mathrm{~h}$, body regions affected, and pain severity. Presence of pain during the past $24 \mathrm{~h}$ was indicated with "yes/no". Then, the participant was asked to mark painful areas on the body with help of a mannequin. Severity of pain was rated on four 11-point numeric rating scales (NRS) for worst, least, and average pain intensity during the past $24 \mathrm{~h}$, and for current pain. The anchors were labelled: $0=$ "no pain" and $10=$ "worst imaginable pain" [41]. The Pain Severity Index (PSI) was established by the average ratings of BPI-SF of worst, average, and current pain. An average of $0-3$ is considered no or mild, 4-6 as moderate and 7-10 as severe pain [42]. The instrument is considered to be valid for several painful conditions [43-45] and has been widely used to evaluate pain in neuromuscular disorders including ALS [7-10, 46]. The internal reliability is high with Chronbach's $\alpha 0.84-0.93$ in participants with noncancer pain, systemic lupus erythematosus and musculoskeletal pain [43-45].

Disease severity was assessed with The Amyotrophic Lateral Sclerosis Functional Rating Scale - Revised Version (ALSFRS-R) [47]. It includes four subscales measuring bulbar, fine motor, gross motor, and respiratory function. Each subscale includes three items ranging from 0 (no function) to 4 (full function) making a total score of 12 for each of the subscales. Lower scores indicate a higher level of dysfunction [47]. The internal consistency reliability is high, Cronbach's $\alpha 0.73$ [47]. The construct validity of the total score correlates with HRQOL measured with the Sickness Impact Profile, $\mathrm{r}_{\mathrm{s}}=-.72$ and with pulmonary function (forced vital capacity \%) $\mathrm{r}_{\mathrm{s}}=.41$ [47].

Demographic data included screening for neuropathic pain $[48,49]$, sex, age, family situation, education, occupational status, MND-diagnosis, time since first symptom of the MND, pharmacotherapy and chronic pain experienced before onset of the MND. The data were collected from the participants at the clinical visit except from data on pharmacotherapy, which were derived from the participants' medical records.

\section{Procedures}

The study was approved by the Regional Ethics Committee in Uppsala, Sweden (approval No. 2015/293). Four MND teams in Sweden were asked to participate in the study and all accepted to participate. Before the start of the study, the first author (YA) informed the data collectors from the different teams about the study procedures and measures and provided them with written information. The number of data collectors in the teams varied from two to six. Eight of the total 15 data collectors were physiotherapists, three were nurses, one was occupational therapist and three were physicians.

Participants were recruited by either the coordinator of the multidisciplinary MND team or the data collector, who sent information letters to eligible participants some weeks before their scheduled clinical visit to the MND team. At the visit, the patients received oral information about the study. The patients confirmed participation by signing an informed consent form. Data were then collected during the clinical visit. In order for the data collection to be at a reasonable length, the BPI-SF [40] was completed at home either on paper or by computer. For those who did not immediately send in their forms, written reminders were sent at the most three times. 


\section{Data management and analysis}

Data from item 1 and 2 in SEIQOL-DW were categorised using a qualitative content analysis. Two of the authors (YA and BJL) initiated the analytic process by grouping areas based on what the participant brought up and how they described them. In the next step, the authors PA and LZ joined the process and contributed with further analyses and re-grouped areas when new consensus was reached. The analysts had different experiences and competencies, where two of the authors (YA, BLJ) had extensive experience of clinical care and physiotherapy treatment for patients with MND and one of physiotherapy treatment of patients with neurological diseases (LZ), and one (PÅ) of physiotherapy and interdisciplinary treatment of patients with chronic pain. One of the authors was a registered nurse (BLJ) the others were registered physiotherapists (YA, LZ, PÅ). A language editor was involved in the translation process of patients 'quotations to secure that their content was kept although translated from Swedish to English.

Non-parametric statistics were used due to data level (ordinal) and data not being normally distributed. Descriptive statistics were used to specify a) the IQOL index (median) i.e. the IQOL on a group level, b) the number of participants with and without pain respectively who nominated each area c) how satisfied the participants were with each nominated area (median), d) participants' pain severity related to each area (mean) e) participants' bulbar, fine motor, gross motor, and respiratory function related to each area. The between-group difference in IQOL scores for participants with and without pain was analyzed with Mann-Whitney U-test. Univariate correlations were calculated between the IQOL score for each participant and pain severity (BPI-SF) and between the IQOL score for each participant and disease severity (ALSFRS-R) using the Spearman's rho. For the latter, calculations were done separately for the four subscales of bulbar function, fine motor function, gross motor function, and respiratory function as recommended by Bakker et al. [50]. A significance level of $p \leq 0.05$ was set. All statistical analyses were performed with the software version SPSS IBM statistics 24 .

\section{Results}

There were in total 154 patients enrolled in the four multidisciplinary teams during the recruitment period. Ninety-five patients met the criteria for inclusion, whereof 61 consented to participate in the study. Figure 1 shows participant flow and number of participants included in the main analyses. No imputations were made for missing data (see Fig. 1).

\section{Participants' characteristics}

Men were almost twice as many as the women (men $n=39$, women $n=22$ ). Most of the participants were retired or had fulltime sick leave. The majority (88.5\%) had either ALS or an MND with only lower motor neuron signs and symptoms and the rest had PLS. Gross and fine motor functions were more commonly affected compared to the bulbar and respiratory functions. Forty-one (74\%) of the participants who answered BPI-SF $(n=55)$ reported pain. Thirty-nine (71\%) of those reported pain during the past $24 \mathrm{~h}$. The severity of pain was classified as moderate (PSI mean $=3.8, \mathrm{SD}=2,4)$, with eight participants $(14 \%)$ reporting severe pain (PSI $\geq 7)$. Participants' characteristics are reported in Table 1.

\section{What constitutes quality of life for people with MND}

The participants nominated altogether 19 areas of importance for their IQOL. The areas are presented in Table 2 together with examples of participants' quotations illustrating the meaning of each area. The areas that most participants described as important for IQOL were "Social relations" $n=35 / 12$ (participants with pain/ without pain), followed by "Activities for amusement and relaxations" $n=23 / 4$ and "Being in the outdoor environment" $n=12 / 7$ (Table 3 ). Five of the areas were only mentioned by the participants who reported pain. These areas were: "A safe and comfortable home environment", "A pet", "Hope for the future", "Having a philosophy of life", and "Being alone".

\section{Individual quality of life and its association with pain, pain severity and disease severity}

The median value for satisfaction with IQOL (index) for the total sample was 5 (25th percentile $=3.25$ and 75 th percentile $=6$ ), representing a good IQOL according to the response format. There was no statistical difference in satisfaction with IQOL between participants with and without pain. Further, there was no statistically significant correlation between pain severity and satisfaction with IQOL, nor between the disease severity and satisfaction with IQOL for any of the four subscales representing disease severity. See Tables 3 and 4.

\section{Discussion}

This study investigated whether pain prevalence and pain severity were associated with IQOL in patients with MND, which to the best of our knowledge not has been undertaken previously in the current population. Overall, satisfaction with IQOL was good and there was no difference in satisfaction with IQOL between participants reporting/not reporting pain. Correlations 


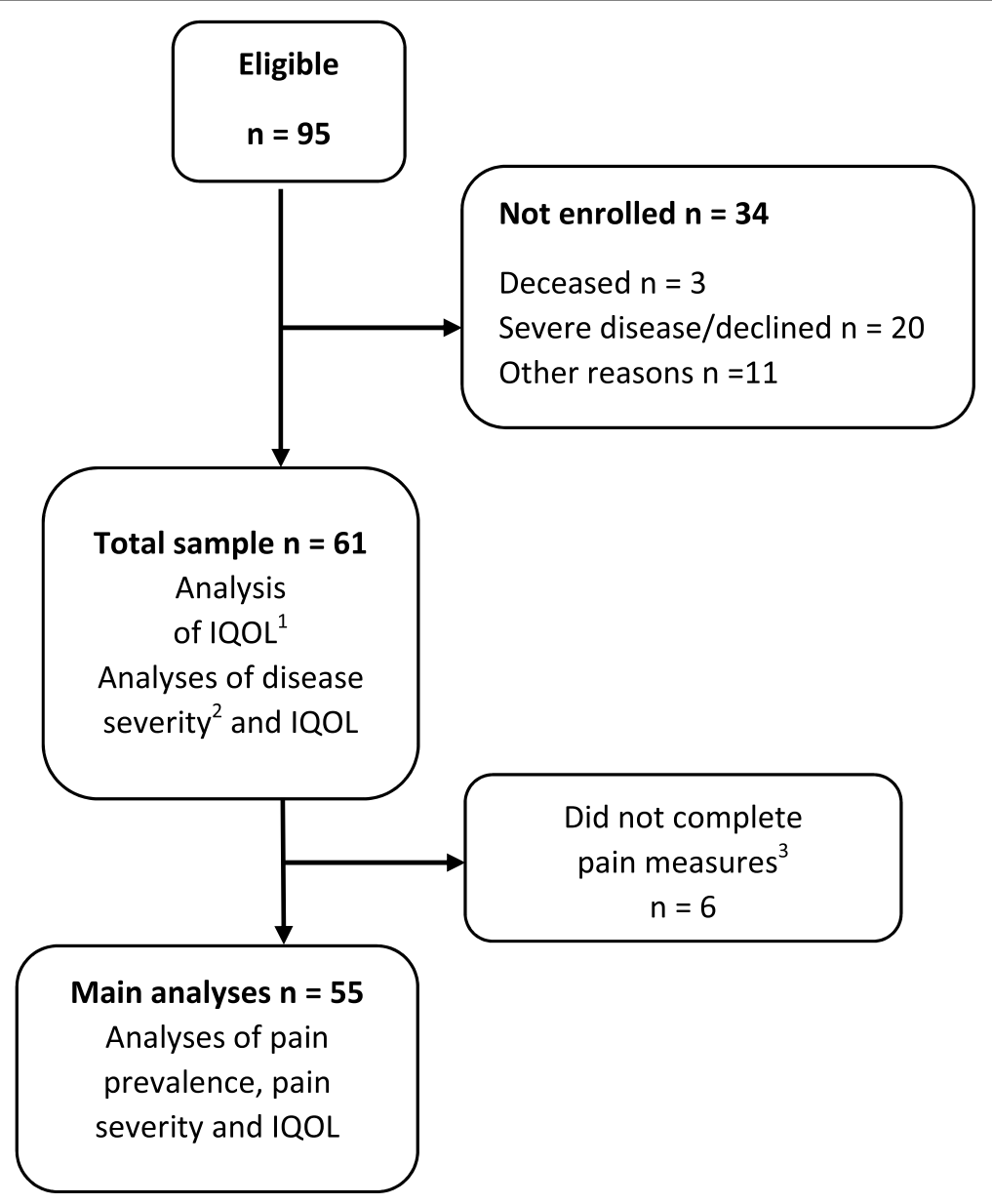

Fig. 1 Patient flow. ${ }^{1}$ Individual Quality of Life measured with a modified version of the Schedule for the Evaluation of Individual Quality of Life - Direct Weighting. ${ }^{2}$ Measured with the Amyotrophic Lateral Sclerosis Functional Rating Scale-Revised version. ${ }^{3}$ Pain prevalence and pain severity measured by the Brief Pain Inventory - Short Form

between pain severity and satisfaction with IQOL, and between disease severity and satisfaction with IQOL were weak and not statistically significant.

Seventy-four percent of the sample reported pain, and $71 \%$ had experienced pain during the past $24 \mathrm{~h}$. Studies on pain prevalence in MND are still scarce and report that pain frequency varies between 15 to $84 \%$ [19]. Our figures were hence at the upper end of this range. Pain severity was on average rated to be moderate, rounded off to the lower end of the range. Fourteen percent reported severe pain, which differs from majority of studies reporting pain to be experienced as mild ( $\leq 3$ on a $0-10$ rating scale) with more severe pain in late stages of the disease [19]. Our study showed that moderate and severe pain could be present in samples with patients in non-terminal stages of the disease. It also confirmed figures reported by [11] pointing to that moderate to severe pain is not a consequence of one small sample only.
On a group level, satisfaction with current IQOL was good, which corresponds to previous studies using the SEIQOL-DW for such evaluation [29-31, 33]. There were some qualitative differences regarding what constitutes the most important areas for IQOL for those reporting pain and for those not reporting pain. Five areas were only expressed by those with pain: "A safe and comfortable home environment", "A pet", "Hope for the future", "Having a philosophy of life", and "Being alone". The sample was too small to draw any conclusions of whether these qualitative differences between those reporting/ not reporting pain are valid on a group level or just an expression of overall individual preferences.

Previous studies have reported that pain does not necessarily interfere with QOL in patients with ALS $[8,10]$, whereas Pizzimenti et al. [11] showed that this association lost its statistical significance when including depression as a covariate in the statistical analysis. We did not include any data on depression, but our results 
Table 1 Patient characteristics

\begin{tabular}{|c|c|}
\hline Patients characteristics, $\mathrm{n}$ & All patients, 61 \\
\hline Gender, male/female n (\%) & $39 / 22(64 / 36)$ \\
\hline Age, all patients, m (SD) & $61.9(12.3)$ \\
\hline \multicolumn{2}{|l|}{ Family situation, n (\%) } \\
\hline Married/cohabitant & $35(57)$ \\
\hline Partner and children & $11(18)$ \\
\hline Single parent & $3(5)$ \\
\hline Single & $12(20)$ \\
\hline \multicolumn{2}{|l|}{ Education, $\mathrm{n}(\%)$} \\
\hline Elementary school & $15(25)$ \\
\hline High school & $24(39)$ \\
\hline University & $22(36)$ \\
\hline \multicolumn{2}{|l|}{ Occupational status, $n,(\%)$} \\
\hline Working full-time & $6(10)$ \\
\hline Working part-time & $5(8)$ \\
\hline Sickness benefit fulltime & $17(28)$ \\
\hline Retired & $31(51)$ \\
\hline Unemployed & $1(2)$ \\
\hline Other & $1(2)$ \\
\hline \multicolumn{2}{|l|}{ Diagnosis, n (\%) } \\
\hline$A L S^{a}$ & $31(51)$ \\
\hline$M N D^{b}$ & $23(38)$ \\
\hline PLSc & $7(12)$ \\
\hline Time since first symptom of disease, $\mathrm{m}$ year (std) & $5,8(7.2)$ \\
\hline \multicolumn{2}{|l|}{ Pain, $\mathrm{BPI}_{\mathrm{S}} \mathrm{F}^{\mathrm{d}}, n=55$} \\
\hline Pain, $n=$ yes $(\%)$ & $41(74)$ \\
\hline Pain during past $24 \mathrm{~h}, n=$ yes (\%) & $39(71)$ \\
\hline Worst level of pain, md (IQR) & $5.0(4.5)$ \\
\hline $\mathrm{PSI}, n=41, \mathrm{~m}(\mathrm{std})$ & $3,8(2,4)$ \\
\hline Neuropathic pain, $n(\%), D N 4^{e}$ & $12(20)$ \\
\hline Chronic pain before onset of MND, $n(\%)$ & $22(36)$ \\
\hline \multicolumn{2}{|l|}{ Disease severity, ALSFRS- $R^{\dagger}$, $m d\left(Q_{1}-Q_{3}\right)$} \\
\hline The bulbar function & $10(7,5-12)$ \\
\hline The fine motor function & $8(4-10)$ \\
\hline The gross motor function & $7(5-9)$ \\
\hline The respiratory function & $12(10-12)$ \\
\hline \multicolumn{2}{|l|}{ Drugs $^{9}, n(\%)$} \\
\hline Analgetics & $6(10)$ \\
\hline Antidepressants & $17(28)$ \\
\hline Antiepileptics & $2(3)$ \\
\hline Anxiolytics & $9(15)$ \\
\hline Hypnotics & $16(26)$ \\
\hline NSAID & $8(13)$ \\
\hline Opioids & $7(12)$ \\
\hline Spasmolytics & $6(10)$ \\
\hline Triptans & $2(3)$ \\
\hline Riluzole & $55(90)$ \\
\hline Nothing & $2(3)$ \\
\hline
\end{tabular}

Table 1 (continued)

a ALS Amyotrohic Lateral Sclerosis with both upper and lower motor neuron
signs and symptoms but not further classified into the specific El Escorial
categories
${ }^{\text {b }}$ MND Motor Neuron Disease with lower motor neuron signs and symptoms
${ }^{c}$ PLS Primary Lateral Sclerosis with only upper motor neuron signs and
symptoms
${ }^{d}$ BPI-SF Brief Pain Inventory Short Form is a self-rating questionnaire about
pain. Pain intensity for worst, least, average and current pain is graded from 0
(no pain) to 10 (pain as bad that you can imagine), PSI Pain Severity Index is the
average score of worst, average and pain perceived at the time of the interview.
No/mild PSI are considered between score 0-3, moderate PSI between scores 4-6
and severe PSI 7-10
e DN4 Doleur Neuropathique 4 questions - Swedish version is a screening
measurement of neuropathic pain
${ }^{f}$ ALSFRS-R Amyotrophic Lateral Sclerosis Functional Rating Scale Revised version
is a 12 -item scale of disease severity of Amyotrophic lateral sclerosis. ALSFRS-R
assesses the level of function in the four domains of bulbar function, fine motor
function, ross motor function and respiratory function. Each item is rated from 0
(worst) to 4 (best), corresponding to a total score of maximum 48
${ }^{9}$ Drugs, Riluzole, improves survival in people with ALS in about 3-6 months and
might have a beneficial effect on neuropathic pain

add to the hypothesis that pain in MND does not necessarily interferes with important aspects of quality of life. The weak associations between pain and IQoL could be an indication of that the participants experienced that pain was under control and possible to cope with. Good IQOL is predicted by coping strategies, in people with ALS [51], which strengthens this assumption. There are other aspects of pain that could be studied to gain further knowledge, e.g. certain pain types, frequency and unpredictability of pain flare-ups, which were perceived as stressful according to a recent study [52], and thus could have a negative impact on satisfaction with IQOL.

In line with previous studies, we found weak and statistically non-significant correlations between IQOL and disease severity [27, 29, 30, 32, 33]. Explanations might be similar to what is described regarding pain, i.e. that people with life threatening diseases tend to cope with their situation by accepting symptoms and disabilities in order to manage to continue life [53]. Additionally, the participants had relatively small impact from their disease on respiratory function, which is crucial for the patients' survival [54]. Reduced variation in respiratory function may explain the absence of correlation between respiratory function as one indicator of disease severity and IQOL. Hence, further studies on respiratory deterioration and its impact on IQOL is recommended.

\section{Methodological considerations}

There are some strengths and limitations of the study that deserve attention. Most importantly, we studied associations using a cross-sectional, and correlational design why causal inferences about the impact of pain on IQOL not could be drawn. Neither could we draw any 


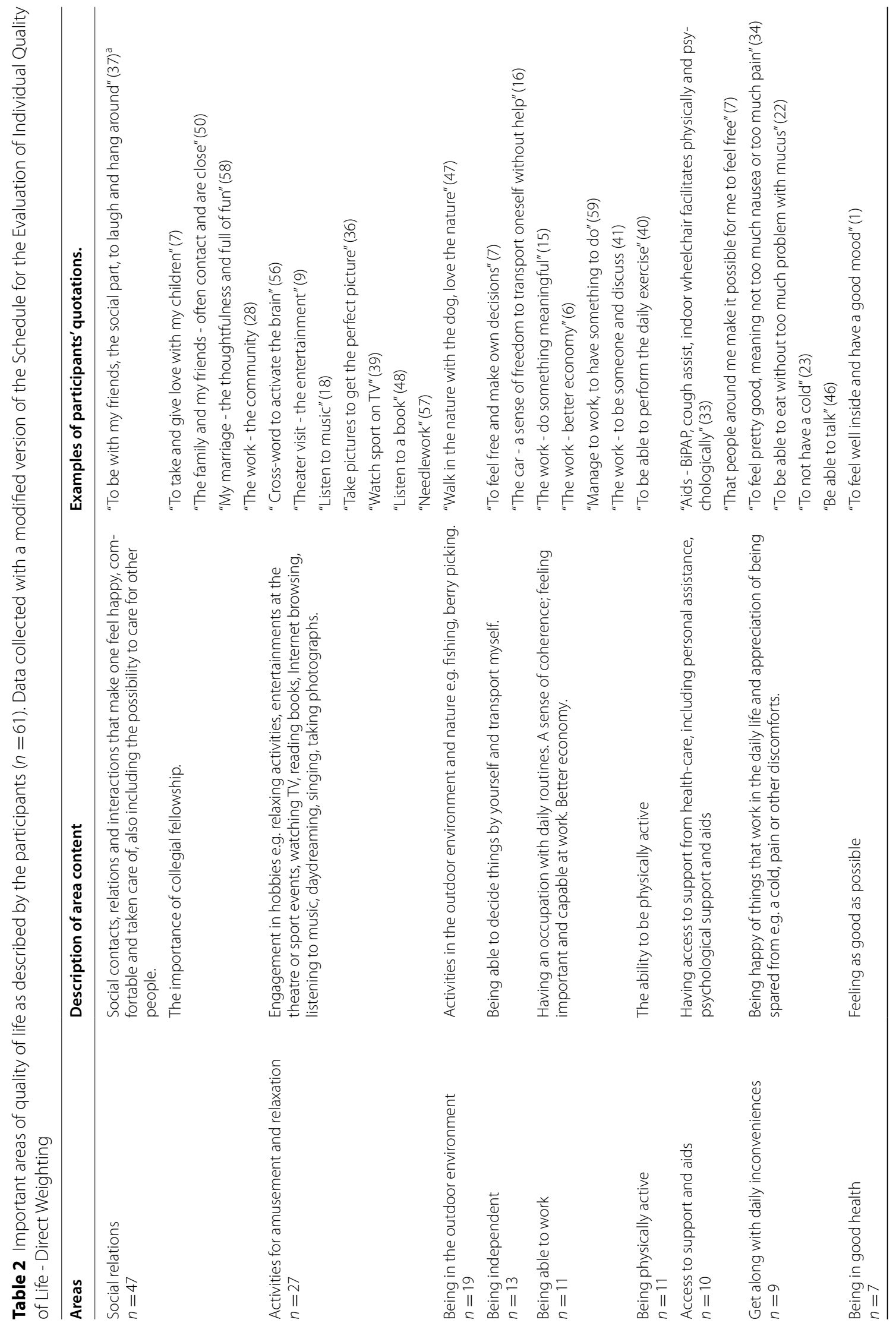




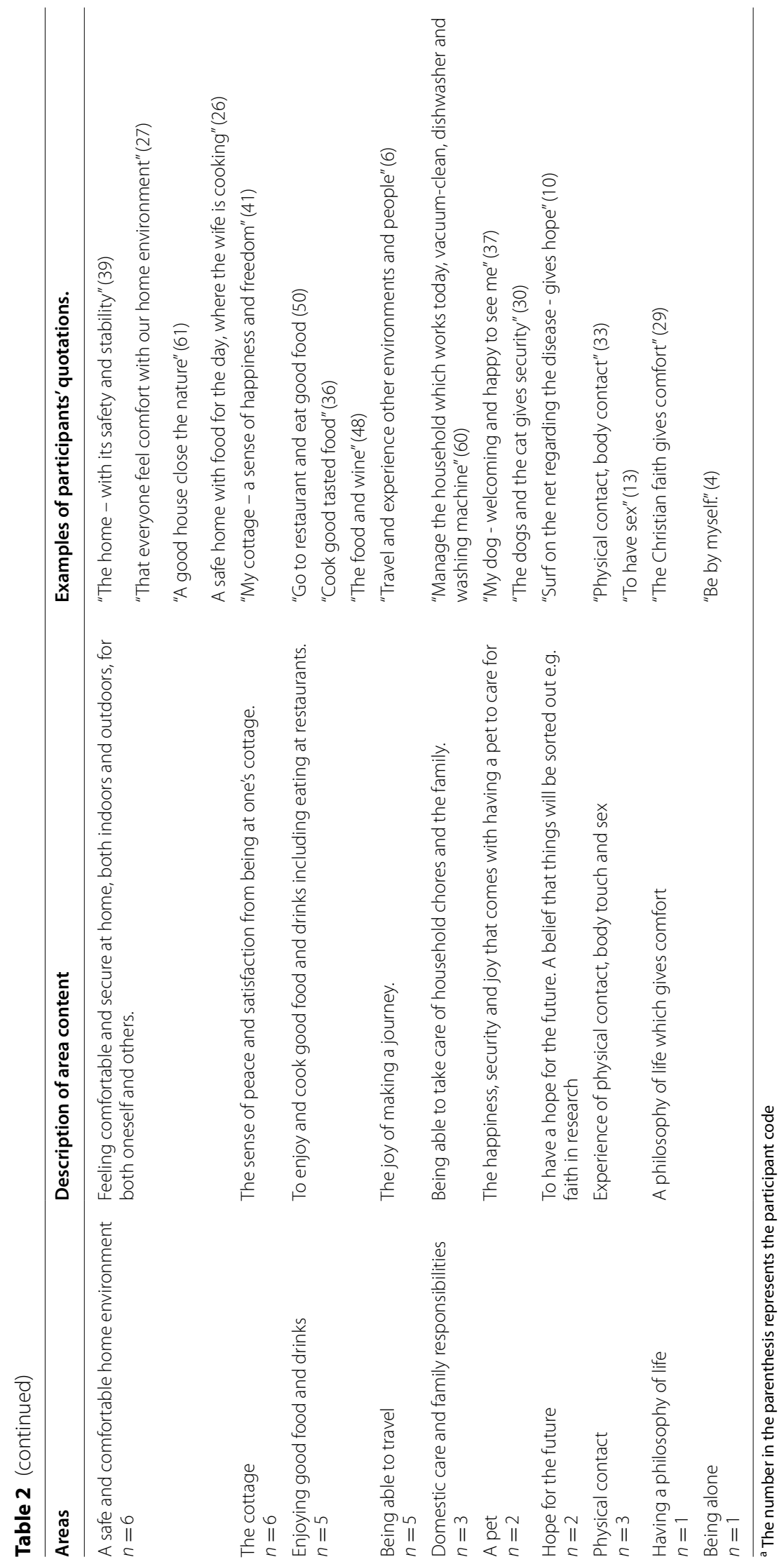


Table 3 Individual quality of life (IQOL): frequency of nominations among those with pain/without pain, level of satisfaction with IQOL among those with/without pain, level of pain severity and disease severity

\begin{tabular}{|c|c|c|c|c|c|c|c|}
\hline Areas $^{\mathrm{a}}$ & $\begin{array}{l}\text { Frequency of } \\
\text { nominations: } \\
\text { participants } \\
\text { with/without } \\
\text { pain } \\
\text { n }(\%)\end{array}$ & $\begin{array}{l}\text { Satisfaction } \\
\text { with IQOL: } \\
\text { participants } \\
\text { with/without } \\
\text { pain', median } \\
\text { (min-max) }\end{array}$ & $\begin{array}{l}\text { Pain severity } \\
\text { Index }{ }^{d} \text { Mean } \\
\text { (SD) }\end{array}$ & $\begin{array}{l}\text { Bulbar } \\
\text { function }{ }^{\mathrm{e}} \\
\text { median (min- } \\
\text { max) }\end{array}$ & $\begin{array}{l}\text { Fine motor } \\
\text { function } \\
\text { median (min- } \\
\text { max) }\end{array}$ & $\begin{array}{l}\text { Gross motor } \\
\text { function } \\
\text { median (min- } \\
\text { max) }\end{array}$ & $\begin{array}{l}\text { Respiratory } \\
\text { function }{ }^{\mathrm{h}}, \\
\text { median (min- } \\
\text { max) }\end{array}$ \\
\hline Social relations & $35(85) / 12(86)$ & $6(2-7) / 6(3-7)$ & $2.8(2.6)$ & $10(0-12)$ & $8(0-12)$ & $7.5(0-12)$ & $12(1-12)$ \\
\hline $\begin{array}{l}\text { Activities for } \\
\text { amusement and } \\
\text { relaxations }\end{array}$ & $23(56) / 4(28)$ & $5(1-7) / 3.8(1-7)$ & $3.1(2.6)$ & $10(0-12)$ & $8(0-11)$ & $7(0-12)$ & $12(1-12)$ \\
\hline $\begin{array}{l}\text { Being in the } \\
\text { outdoor environ- } \\
\text { ment }\end{array}$ & $12(29) / 7(50)$ & $5.5(3-7) / 5(1-6)$ & $1.6(1.8)$ & $10(0-12)$ & $8(1-12)$ & $8(0-12)$ & $12(4-12)$ \\
\hline $\begin{array}{l}\text { Being independ- } \\
\text { ent }\end{array}$ & $9(22) / 4(28)$ & $4(1-6) / 4.5(1-6)$ & $3.0(2.8)$ & $11(3-12)$ & $8(1-11)$ & $7(2-12)$ & $11(4-12)$ \\
\hline $\begin{array}{l}\text { Being able to } \\
\text { work }\end{array}$ & $9(22) / 2(14)$ & $4(1-6) / 5.5(5-6)$ & $3.8(2.8)$ & $10(4-12)$ & $8(1-12)$ & $8(5-12)$ & $11(4-12)$ \\
\hline $\begin{array}{l}\text { Being physically } \\
\text { active }\end{array}$ & $9(22) / 2(14)$ & $4(1-7) / 2(1-3)$ & $3.1(2.9)$ & $10(3-12)$ & $9(1-12)$ & $7(0-12)$ & $12(5-12)$ \\
\hline $\begin{array}{l}\text { Acess to support } \\
\text { and aids }\end{array}$ & $8(20) / 2(14)$ & $6(2-7) / 6.5(6-7)$ & $3.6(2.3)$ & $10.5(3-12)$ & $7.5(1-10)$ & $5(1-12)$ & $12(1-12)$ \\
\hline $\begin{array}{l}\text { Get along with } \\
\text { daily inconven- } \\
\text { iences }\end{array}$ & $6(15) / 3(21)$ & $3.5(1-6) / 3(2-6)$ & $2.7(2.4)$ & $8(0-12)$ & $7.5(0-12)$ & $7(0-12)$ & $10(2-12)$ \\
\hline $\begin{array}{l}\text { Being in good } \\
\text { health }\end{array}$ & $3(7) / 4(28)$ & $6(2-6) / 5.5(4-6)$ & $2.3(2.4)$ & $9(3-12)$ & $8(0-12)$ & $5(1-12)$ & $11(8-12)$ \\
\hline $\begin{array}{l}\text { A safe and com- } \\
\text { fortable home } \\
\text { environment }\end{array}$ & $6(15) / 0$ & $6(4-7)$ & $4.2(2.1)$ & $10(3-12)$ & $6(0-12)$ & $8(0-10)$ & $12(1-12)$ \\
\hline The cottage & $4(10) / 2(14)$ & $6(5-7) / 4(1-7)$ & $3.1(2.8)$ & $9.5(3-12)$ & $10(0-12)$ & $7.5(2-10)$ & $11.5(5-12)$ \\
\hline $\begin{array}{l}\text { Enjoying good } \\
\text { food and drinks }\end{array}$ & $3(7) / 2(14)$ & $6(4-6) / 6.5(6-7)$ & $1.6(1.6)$ & $8(3-12)$ & $8(1-11)$ & $8(0-12)$ & $12(4-12)$ \\
\hline $\begin{array}{l}\text { Being able to } \\
\text { travel }\end{array}$ & $4(10) / 1(7)$ & $6(1-7) / 5$ (N/a) & $4.3(3.4)$ & $12(10-12)$ & $10(9-10)$ & $8(2-9)$ & $12(8-12)$ \\
\hline $\begin{array}{l}\text { Domestic care } \\
\text { and family } \\
\text { responsibilities }\end{array}$ & $1(2) / 2(14)$ & $4(\mathrm{~N} / \mathrm{a}) / 3.5(3-4)$ & $0.9(1.6)$ & $8(7-10)$ & $10(5-12)$ & $11(5-12)$ & $12(10-12)$ \\
\hline A pet & $2(5) / 0$ & $6.5(6-7)$ & $8.4(0.9)$ & $12(11-12)$ & $7(4-7)$ & $8(7-9)$ & $12(11-12)$ \\
\hline $\begin{array}{l}\text { Hope for the } \\
\text { future }\end{array}$ & $2(5) / 0$ & $3.5(1-6)$ & $2.6(0.5)$ & $11.5(11-12)$ & $7.5(7-8)$ & $3.5(1-6)$ & $8(4-12)$ \\
\hline Physical contact & $1(2) / 2(14)$ & $4(\mathrm{~N} / \mathrm{a}) / 1.5(1-2)$ & $2.4(2.1)$ & $8(6-12)$ & $3(0-4)$ & $4(1-6)$ & $11(1-11)$ \\
\hline $\begin{array}{l}\text { Having a philoso- } \\
\text { phy of life }\end{array}$ & 1 (2) /0 & $5.5(\mathrm{~N} / \mathrm{a})$ & $1.3(\mathrm{~N} / \mathrm{a})$ & $8.0(\mathrm{~N} / \mathrm{a})$ & 6.0 (N/a) & $8.0(\mathrm{~N} / \mathrm{a})$ & $12.0(\mathrm{~N} / \mathrm{a})$ \\
\hline Being alone & $1(2) / 0$ & $5(\mathrm{~N} / \mathrm{a})$ & 4.7 (N/a) & $8.0(\mathrm{~N} / \mathrm{a})$ & $3.0(\mathrm{~N} / \mathrm{a})$ & 7.0 (N/a) & $6.0(\mathrm{~N} / \mathrm{a})$ \\
\hline
\end{tabular}

${ }^{a}$ Areas nominated as important for individual quality of life (IQOL). ${ }^{b}$ participants with/without pain nominating the area. ${ }^{c}$ How satisfied participants with pain were

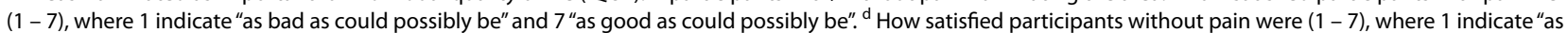
bad as could possibly be" and 7 "as good as could possibly be". " Pain Severity Index (PSI) = average of ratings of worst, average and current pain during the past 24 hours. ${ }^{\mathrm{f}}$ Bulbar function, ${ }^{\mathrm{g}}$ fine motor function, ${ }^{\mathrm{h}}$ gross motor function and ${ }^{\mathrm{i}}$ respiratory function as subscales of the Amyotrophic Lateral Sclerosis Rating Scale - Revised version (ALSFRSR). Scores ranging from 0-12 on each subscale, where lower scores indicate worse function

Table 4 Individual of quality of life and its association with pain severity (Brief Pain Inventory - Short form), disease severity (ALSFRS-R) and individual quality of life (SEIQOL-DW)

\begin{tabular}{llllll}
\hline & Pain severity $(\boldsymbol{n}=\mathbf{5 5})$ & $\begin{array}{l}\text { Bulbar function } \\
(\boldsymbol{n}=\mathbf{6 1 )}\end{array}$ & $\begin{array}{l}\text { Fine motor function } \\
(\boldsymbol{n}=\mathbf{6 1 )}\end{array}$ & $\begin{array}{l}\text { Gross motor } \\
\text { function }(\boldsymbol{n}=\mathbf{6 1 )}\end{array}$ & $\begin{array}{l}\text { Respiratory } \\
\text { function } \\
(\boldsymbol{n}=\mathbf{6 1 )}\end{array}$ \\
\hline Individual quality of life & $r_{s}{ }^{1}=-.007$ & $r_{s}{ }^{1}=.087$ & $r_{s}{ }^{1}=.101$ & $r_{s}{ }^{1}=.181$ & $r_{s}{ }^{1}=.069$ \\
& $p=.96$ & $p=.50$ & $p=.44$ & $p=.163$ & $p=.598$ \\
\hline
\end{tabular}


conclusion about the influence of pain in relation to how IQOL varies/not varies over time. Our results thus add to the specification of hypotheses that need to be further investigated.

We used an established, standardized method to assess pain and pain severity, the BPI-SF, adhering to previous attempts to make pain studies in MND more comparable. Considering the construct of QOL, we chose an individual perspective on what areas of life that were important for a good quality of life when facing a degenerative disease. The individual perspective has high clinical relevance and can be a cornerstone when planning for the patient's care. A limitation with the use of the measure could be if the participants may have chosen to nominate areas that were functioning well and omitted areas where they experienced physical limitations and negative emotions, resulting in a higher IQOL index [55].

The SEIQoL-DW offers an inductive method to collect and analyzing data, which is seldom strictly adhered to $[38,56]$. In this study, participants were asked to nominate areas of importance all by themselves, without using the commonly applied prompt-list with pre-defined areas possible to nominate as important for QOL. This procedure secured the individual perspective and was well accepted and easily undertaken. To increase credibility of the inductive analysis, researcher triangulation was performed in several steps, and all accounts were sorted into areas after consensus agreements between researchers. To get a valid estimation of disease severity, we operationalized disease severity by reporting the results for the four subscales of ALSFRS-R separately, which has recently been recommended [50].

We recruited patients from four different MND teams to enhance variation and recruitment of as many participants as possible during a given time period. Patients with distinct cognitive impairment were not eligible for the study. Between 35 and $45 \%$ of the ALS population suffer from cognitive impairments [57], and our findings should therefore not be extrapolated to this subgroup of patients. We did not include patients with difficulties in speaking and understanding the Swedish language, and there was a limited number of participants who were in the severe stage of the disease, which both could threaten external validity. Finally, the proportion of participants with PLS was slightly higher compared to what is representative for the MND, that is expected to be 1-4\% [5].

Ethical considerations on risks and benefits of participation Consideration was as far as possible given to the total time of the participants' clinical visit, concerning the risk that participants were getting exhausted after their clinic visit due to the extra burden of study participation. The benefits of contributing to research by sharing experiences and reflections about their current life situation, and with the prospect to increase the understanding of what is important for people living with MND were assumed to exceed the burden of participation.

\section{Conclusions}

The results add to the hypothesis that associations between pain prevalence and pain severity and IQOL are weak in MND. However, pain prevalence was high and the results pointed to that some participants experienced a high pain severity. Hence, pain can be a source of distress in itself, indicating that systematic tools for pain assessment and pain treatments tailored to the specific needs of the MND population should be developed and scientifically evaluated.

\section{Abbreviations \\ ALS: Amyotrophic lateral sclerosis; MND: Motor neuron disease; PLS: Primary Lateral Sclerosis; QOL: Quality of life; HRQOL: Health related quality of life; IQOL: Individual quality of life; Modified Swedish SEIQoL-DW: The Modified Swedish Schedule for the Evaluation of Individual Quality of Life - Direct Version; ALSFRS-R: The Amyotrophic Lateral Sclerosis Functional Rating Scale - Revised Version; BPI-SF: The Brief Pain Inventory - Short-form.}

\section{Acknowledgements}

We are grateful to all the participants, who took part in the study and to the data collectors, who enabled the study to be performed.

\section{Authors' contributions}

YÅ: formulation of research questions, preparation of data, analysis, interpretation of the data, preparation and writing of the manuscript. LZ: formulation of research questions, interpretation of data, and preparation of the manuscript. $B J \mathrm{~L}$ : recruitment of the patients, interpretation of data, and preparation of the manuscript. DN: formulation of research questions, interpretation of data and preparation of the manuscript. IN: formulation of research questions, preparation of the manuscript. PÅ: formulation of research questions, interpretation of data, preparation, writing, and revision of the manuscript. The author(s) read and approved the final manuscript.

\section{Funding}

This work was supported by the County Council of Uppsala; the funding of agreements on medical education and research Uppsala University Hospital, the Uppsala University medical faculty's funding for caring sciences, the Neuro Federation of Sweden and by grants from Ulla-Carin Lindquist foundation. The contents of this publication are solely the responsibility of the authors. Open access funding provided by Uppsala University.

\section{Availability of data and materials}

The datasets used and/or analyzed during the current study are available from the corresponding author on reasonable request.

\section{Declarations}

\section{Ethics approval and consent to participate}

The study has been performed in accordance with the Declaration of Helsinki. Study procedures adhered to guidelines for Good Clinical Practices. The study was approved by the Regional Ethics Committee in Uppsala, Sweden (approval No. 2015/293) and the patients confirmed participation by signing an informed consent form.

Involving animals

Not applicable.

Consent for publication

Not applicable. 


\section{Competing interests}

The authors declare that they have no competing interests.

\section{Author details}

${ }^{1}$ Department of Neuroscience, Physiotherapy, Uppsala University, Box 593 BMC, 75124 Uppsala, Sweden. ${ }^{2}$ Department of Public Health and Caring Sciences, Uppsala University, Box 564, 75422 Uppsala, Sweden. ${ }^{3}$ Department of Neuroscience, Neurology, Uppsala University, 75185 Uppsala, Sweden.

Received: 11 June 2021 Accepted: 9 September 2021

Published online: 12 October 2021

\section{References}

1. Tiryaki E, Horak HA. ALS and other motor neuron diseases. Continuum (Minneapolis, Minn). 2014;20(5 Peripheral Nervous System Disorders):1185-207.

2. Lopes LCG, Galhardoni R, Silva V, Jorge FMH, Yeng LT, Callegaro D, et al. Beyond weakness: characterization of pain, sensory profile and conditioned pain modulation in patients with motor neuron disease: a controlled study. Eur J Pain. 2018;22(1):72-83.

3. Logroscino G, Piccininni M. Amyotrophic lateral sclerosis descriptive epidemiology: the origin of geographic difference. Neuroepidemiology. 2019;52(1-2):93-103.

4. Wood-Allum C, Shaw PJ. Motor neurone disease: a practical update on diagnosis and management. Clin Med. 2010;10(3):252-8.

5. Statland JM, Barohn RJ, Dimachkie MM, Floeter MK, Mitsumoto H. Primary lateral sclerosis. Neurol Clin. 2015;33(4):749-60.

6. Sepulveda C, Marlin A, Yoshida T, Ullrich A. Palliative care: the World Health Organization's global perspective. J Pain Symptom Manag. 2002;24(2):91-6.

7. Hanisch F, Skudlarek A, Berndt J, Kornhuber ME. Characteristics of pain in amyotrophic lateral sclerosis. Brain Behav. 2015;5(3):e00296.

8. Chio A, Canosa A, Gallo S, Moglia C, Ilardi A, Cammarosano S, et al. Pain in amyotrophic lateral sclerosis: a population-based controlled study. Eur J Neurol. 2012;19(4):551-5.

9. Stephens HE, Lehman E, Raheja D, Yang C, Walsh S, McArthur DB, et al. Pain in amyotrophic lateral sclerosis: patient and physician perspectives and practices. Amyotroph Lateral Scler Frontotemporal Degener. 2015;17(1-2):21-9.

10. Wallace VC, Ellis CM, Burman R, Knights C, Shaw CE, Al-Chalabi A. The evaluation of pain in amyotrophic lateral sclerosis: a case controlled observational study. Amyotroph Lateral Scler Frontotemporal Degener. 2014;15(7-8):520-7.

11. Pizzimenti A, Aragona M, Onesti E, Inghilleri M. Depression, pain and quality of life in patients with amyotrophic lateral sclerosis: a cross-sectional study. Funct Neurol. 2013;28(2):115-9.

12. Rivera I, Ajroud-Driss S, Casey P, Heller S, Allen J, Siddique T, et al. Prevalence and characteristics of pain in early and late stages of ALS. Amyotroph Lateral Scler Frontotemporal Degener. 2013;14(5-6):369-72.

13. Sandstedt P, Littorin S, Johansson S, Gottberg K, Ytterberg C, Kierkegaard M. Disability and contextual factors in patients with amyotrophic lateral sclerosis - a three-year observational study. J Neuromuscul Dis. 2018;5(4):439-49.

14. World Health O. Cancer control: knowledge into action : WHO guide for effective programmes. Geneva:WHO; 2006.

15. Brettschneider J, Kurent J, Ludolph A. Drug therapy for pain in amyotrophic lateral sclerosis or motor neuron disease. Cochrane Database Syst Rev. 2008;(3):CD005226. https://doi.org/10.1002/14651858.CD005226. pub2.

16. Maggiani A, Tremolizzo L, Della Valentina A, Mapelli L, Sosio S, Milano V, et al. Osteopathic manual treatment for amyotrophic lateral sclerosis: a feasibility pilot study. Open Neurol J. 2016;10:59-66.

17. Green S, Buchbinder R, Hetrick S. Physiotherapy interventions for shoulder pain. Cochrane Database Syst Rev. 2003;(2):CD004258. https://doi. org/10.1002/14651858.CD004258.

18. Green S, Buchbinder R, Hetrick S. Acupuncture for shoulder pain. Cochrane Database Syst Rev. 2005;(2):CD005319. https://doi.org/10.1002/ 14651858.CD005319.
19. Chio A, Mora G, Lauria G. Pain in amyotrophic lateral sclerosis. Lancet Neurol. 2017;16(2):144-57.

20. Testa MA, Simonson DC. Assessment of quality-of-life outcomes. N Engl J Med. 1996;334(13):835-40.

21. Simmons Z. Patient-perceived outcomes and quality of life in ALS. Neurotherapeutics. 2015;12(2):394-402.

22. Ware JE Jr, Sherbourne CD. The MOS 36-item short-form health survey (SF-36). I. Conceptual framework and item selection. Med Care. 1992:30(6):473-83.

23. Prell T, Gaur N, Stubendorff B, Rodiger A, Witte OW, Grosskreutz J. Disease progression impacts health-related quality of life in amyotrophic lateral sclerosis. J Neurol Sci. 2019;397:92-5.

24. Sandstedt P, Johansson S, Ytterberg C, Ingre C, Holmqvist LW, Kierkegaard M. Predictors of health-related quality of life in people with amyotrophic lateral sclerosis. J Neurol Sci. 2016;370:269-73.

25. Burns TM, Graham CD, Rose MR, Simmons Z. Quality of life and measures of quality of life in patients with neuromuscular disorders. Muscle Nerve. 2012;46(1):9-25.

26. Hickey AM, Bury G, O'Boyle CA, Bradley F, O'Kelly FD, Shannon W. A new short form individual quality of life measure (SEIQOL-DW): application in a cohort of individuals with HIV/AIDS. BMJ. 1996;313(7048):29-33.

27. Chio A, Gauthier A, Montuschi A, Calvo A, Di Vito N, Ghiglione P, et al. A cross sectional study on determinants of quality of life in ALS. J Neurol Neurosurg Psychiatry. 2004;75(11):1597-601.

28. Goldstein LH, Atkins L, Leigh PN. Correlates of quality of life in people with motor neuron disease (MND). Amyotroph Lateral Scler Other Motor Neuron Disord. 2002:3(3):123-9.

29. Felgoise SH, Stewart JL, Bremer BA, Walsh SM, Bromberg MB, Simmons Z. The SEIQOL-DW for assessing quality of life in ALS: strengths and limitations. Amyotroph Lateral Scler. 2009;10(5-6):456-62.

30. Jakobsson Larsson B, Ozanne AG, Nordin K, Nygren I. A prospective study of quality of life in amyotrophic lateral sclerosis patients. Acta Neurol Scand. 2017;136(6):631-8.

31. Olsson AG, Markhede I, Strang S, Persson LI. Differences in quality of life modalities give rise to needs of individual support in patients with ALS and their next of kin. Palliat Support Care. 2010;8(1):75-82.

32. Neudert C, Wasner M, Borasio GD. Individual quality of life is not correlated with health-related quality of life or physical function in patients with amyotrophic lateral sclerosis. J Palliat Med. 2004;7(4):551-7.

33. Tramonti F, Bongioanni P, Di Bernardo C, Davitti S, Rossi B. Quality of life of patients with amyotrophic lateral sclerosis. Psychol Health Med. 2012:17(5):621-8.

34. Ganzini L, Johnston WS, Hoffman WF. Correlates of suffering in amyotrophic lateral sclerosis. Neurology. 1999;52(7):1434-40.

35. Querin G, Soraru G, Pradat PF. Kennedy disease (X-linked recessive bulbospinal neuronopathy): a comprehensive review from pathophysiology to therapy. Rev Neurol (Paris). 2017;173(5):326-37.

36. Wettergren L, Bjorkholm M, Axdorph U, Bowling A, Langius-Eklof A. Individual quality of life in long-term survivors of Hodgkin's lymphoma--a comparative study. Qual Life Res. 2003;12(5):545-54.

37. Wettergren L, Bjorkholm M, Langius-Eklof A. Validation of an extended version of the SEIQoL-DW in a cohort of Hodgkin lymphoma' survivors. Qual Life Res. 2005;14(10):2329-33.

38. Wettergren $L$, Kettis-Lindblad A, Sprangers $M$, Ring $L$. The use, feasibility and psychometric properties of an individualised quality-of-life instrument: a systematic review of the SEIQoL-DW. Qual Life Res. 2009;18(6):737-46.

39. Neudert C, Oliver D, Wasner M, Borasio GD. The course of the terminal phase in patients with amyotrophic lateral sclerosis. J Neurol. 2001:248(7):612-6.

40. Cleeland CS, Ryan KM. Pain assessment: global use of the brief pain inventory. Ann Acad Med Singap. 1994:23(2):129-38.

41. Cleeland CS. The brief pain inventory: user guide. Houston; 2009. Available from: https://www.mdanderson.org/documents/.../BPI_UserGuide. pdf. Cited 21 Aug 2017.

42. Hoffman DL, Sadosky A, Dukes EM, Alvir J. How do changes in pain severity levels correspond to changes in health status and function in patients with painful diabetic peripheral neuropathy? Pain. 2010;149(2):194-201.

43. de Andres Ares J, Cruces Prado LM, Canos Verdecho MA, Penide Villanueva L, Del Valle Hoyos M, Herdman M, et al. Validation of the short 
form of the brief pain inventory (BPI-SF) in Spanish patients with noncancer-related pain. Pain Pract. 2015;15(7):643-53.

44. Naegeli AN, Tomaszewski EL, Al Sawah S. Psychometric validation of the brief pain inventory-short form in patients with systemic lupus erythematosus in the United States. Lupus. 2015;24(13):1377-83.

45. Celik EC, Yalcinkaya EY, Atamaz F, Karatas M, Ones K, Sezer T, et al. Validity and reliability of a Turkish brief pain inventory short form when used to evaluate musculoskeletal pain. J Back Musculoskelet Rehabil. 2017;30(2):229-33.

46. Hoffman AJ, Jensen MP, Abresch RT, Carter GT. Chronic pain in persons with neuromuscular disease. Phys Med Rehabil Clin N Am. 2005;16(4):1099-112 xii.

47. Cedarbaum JM, Stambler N, Malta E, Fuller C, Hilt D, Thurmond B, et al. The ALSFRS-R: a revised ALS functional rating scale that incorporates assessments of respiratory function. BDNF ALS Study Group (Phase III). J Neurol Sci. 1999;169(1-2):13-21.

48. Bouhassira D, Attal N, Fermanian J, Alchaar H, Gautron M, Masquelier E, et al. Development and validation of the neuropathic pain symptom inventory. Pain. 2004;108(3):248-57.

49. Hallström $H$, Norrbrink C. Screening tools for neuropathic pain: can they be of use in individuals with spinal cord injury? Pain. 2011;152(4):772-9.

50. Bakker LA, Schroder CD, van Es MA, Westers P, Visser-Meily JMA, van den Berg LH. Assessment of the factorial validity and reliability of the ALSFRSR: a revision of its measurement model. J Neurol. 2017;264(7):1413-20.

51. Matuz T, Birbaumer N, Hautzinger M, Kubler A. Psychosocial adjustment to ALS: a longitudinal study. Front Psychol. 2015;6:1197.
52. Akerblom Y, Jakobsson Larsson B, Zetterberg L, Asenlof P. The multiple faces of pain in motor neuron disease: a qualitative study to inform pain assessment and pain management. Disabil Rehabil. 2020;42(15):2123-32.

53. Anderson M, Asnani M. "You just have to live with it": coping with sickle cell disease in Jamaica. Qual Health Res. 2013;23(5):655-64.

54. Wijesekera LC, Mathers S, Talman P, Galtrey C, Parkinson MH, Ganesalingam J, et al. Natural history and clinical features of the flail arm and flail leg ALS variants. Neurology. 2009;72(12):1087-94.

55. Korner S, Kollewe K, Abdulla S, Zapf A, Dengler R, Petri S. Interaction of physical function, quality of life and depression in Amyotrophic lateral sclerosis: characterization of a large patient cohort. BMC Neurol. 2015;15:84.

56. Taminiau-Bloem EF, Visser MR, Tishelman C, Koeneman MA, van Zuuren FJ, Sprangers MA. Somatically ill persons' self-nominated quality of life domains: review of the literature and guidelines for future studies. Qual Life Res. 2010;19(2):253-91.

57. Pender N, Pinto-Grau M, Hardiman O. Cognitive and behavioural impairment in amyotrophic lateral sclerosis. Curr Opin Neurol. 2020;33(5):649-54.

\section{Publisher's Note}

Springer Nature remains neutral with regard to jurisdictional claims in published maps and institutional affiliations.
Ready to submit your research? Choose BMC and benefit from:

- fast, convenient online submission

- thorough peer review by experienced researchers in your field

- rapid publication on acceptance

- support for research data, including large and complex data types

- gold Open Access which fosters wider collaboration and increased citations

- maximum visibility for your research: over 100M website views per year

At BMC, research is always in progress.

Learn more biomedcentral.com/submissions 